International Journal of Control Theory and Computer Modelling (IJCTCM) Vol.2, No.6, November 2012

\title{
Performances of MOdel Reduction USING FACTOR DIVISION AlgorithM AND EIGEN SPECTRUM ANALYSIS
}

\author{
Amel Baha Houda Adamou-Mitiche and Lahcène Mitiche \\ Science and Technology Department, University of Djelfa, BP 3047, Ain \\ Chih, Djelfa, 17000, Algeria \\ amelmitiche@yahoo.fr, I_mitiche@yahoo.fr
}

\begin{abstract}
The easy and simplicity of manipulation and the multiple applications provided by approximate reducedorder systems, in comparison with original high order systems, make the topic of model reduction a subject with big importance; it allows us to get models that approached in their behavior, by satisfactory way, the high order original systems.

In this paper we study one of recent reduction methods, which combine the algorithm of factor division and eigen spectrum analysis, and we compare it in the time domain (Schur method), and in the frequency domain (Routh approximation approach), in order to determine its performances.
\end{abstract}

\section{KEYWORDS}

High order systems, Model reduction, Factor division, Eigen spectrum analysis, Schur method, Routh approximation.

\section{INTRODUCTION}

In recent years, the problem of simplifying the model has been the subject of much research because the study of direct practice such systems necessarily leads to costs as well as extremely high computation time, this is due to the use of numerical algorithms whose convergence is sometimes difficult and often impossible when the size of the process to be studied is large. Therefore, the reduction becomes a tool more than necessary. The reduction technique is to define a model of reduced dimension, retaining the main physical aspects of the initial system and its features, such as stability. The approximation of complex model is a large area, several studies were performed, each algorithm can be applied to a given problem [1,2]. In our work, we study a new technique for order reduction of large systems that combines factor division algorithm and spectral analysis to obtain a reduced order. Therefore, by comparing this approach with existing others, interesting results are obtained, as it will be shown by simulations performed in MATLAB ${ }^{\circledR} 7.1$.

\section{ROUTH APPROXIMATION METHOD (RAM)}

It is simple and direct method, based on the Routh stability criterion. The reduced order transfer function is determined directly from elements in the Routh stability arrays of high-

DOI : 10.5121/ijctcm.2012.2601 
International Journal of Control Theory and Computer Modelling (IJCTCM) Vol.2, No.6, November 2012 order denominator and numerator.

\section{Model reduction Procedure [8]}

Input : The strictly proper high-order system $n$ represented by

$$
H(s)=\frac{b_{11} s^{m}+b_{21} s^{m-1}+b_{12} s^{m-2}+b_{22} s^{m-3}+\ldots}{a_{11} s^{n}+a_{21} s^{n-1}+a_{12} s^{n-2}+a_{22} s^{n-3}+\ldots},
$$

Step1 : The Routh stability array for the numerator and denominator polynomials of $\mathrm{H}(\mathrm{s})$ are shown below in Tables1 and 2, respectively.

Table 1. Numerator Stability

Array

$$
\begin{array}{lllll}
\mathrm{b}_{11} & \mathrm{~b}_{12} & \mathrm{~b}_{13} & \mathrm{~b}_{14} & \ldots \\
\mathrm{b}_{21} & \mathrm{~b}_{22} & \mathrm{~b}_{23} & \mathrm{~b}_{24} & \ldots \\
-- & \cdots & - & - & - \\
\mathrm{b}_{31} & \mathrm{~b}_{32} & \mathrm{~b}_{33} & \ldots & \\
\mathrm{b}_{41} & \mathrm{~b}_{42} & \mathrm{~b}_{43} & \cdots & \\
\cdot & & & & \\
\cdot & & & & \\
\mathrm{b}_{\mathrm{m}, 1} & & & \\
\mathrm{~b}_{\mathrm{m}+1,1} & & &
\end{array}
$$

Table 2. Denominator Stability

Array

$$
\begin{array}{lllll}
a_{11} & a_{12} & a_{13} & a_{14} & \ldots \\
a_{21} & a_{22} & a_{23} & a_{24} & \ldots \\
--- & \ldots & - \\
- & -- & --- & \\
a_{31} & a_{32} & a_{33} & \ldots & \\
a_{41} & a_{42} & a_{43} & \ldots & \\
\cdot & & & & \\
\cdot & & & & \\
a_{n, 1} & & & & \\
a_{n+1,1} & & &
\end{array}
$$

Step2: The tables coefficients are calculated by

$$
C_{i j}=C_{i-2, j+1}-\left(C_{i-2,1} \cdot C_{i-1, j+1}\right) /\left(C_{i-1,1}\right), \mathrm{i} \geq 3,1 \leq \mathrm{j} \leq(\mathrm{n}-\mathrm{i}+3) / 2,
$$

Output: Construction of the reduced order $\mathrm{H}_{\mathrm{r}}(\mathrm{s})$ transfer-function of a system with reduced order: 
International Journal of Control Theory and Computer Modelling (IJCTCM) Vol.2, No.6, November 2012

$$
H_{r}(s)=\frac{b_{(m+2-r), 1} s^{r-1}+b_{(m+3-r), 1} s^{r-2}+\ldots}{a_{(n+1-r), 1} s^{r}+a_{(n+2-r), 1} s^{r-1}+\ldots}
$$

\section{End of procedure.}

\section{SCHUR Method (NONMINIMAL MODELS)}

The Schur method can be computed the Moore reduced model directly without passing by balanced state space realization, via projections defined in terms of arbitrary bases for left and right eigenspaces associated with the large eigenvalues of the product of the controllability and observability gramians $\left(W_{c} W_{o}\right)$.

\section{Procedure [9]}

Input: The complete order system $n$ have state space realization $(A, B, C, D, n)$.

Step1: Resolve Lyapunov equations to get the controllability and observability gramians $W_{c}, W_{o}$.

Step 2: Compute an orthogonal real matrix $V$, such that $\left(\mathrm{V} \cdot \mathrm{W}_{\mathrm{c}} \cdot \mathrm{W}_{\mathrm{o}} \cdot \mathrm{V}^{\mathrm{T}}\right)$ is upper triangular, i.e., put $\left(W_{c} \cdot W_{o}\right)$ into Schur form.

Step3 : Using orthogonal rotations for compute orthogonal real transformations which order the Schur forms in ascending and descending order, respectively such that

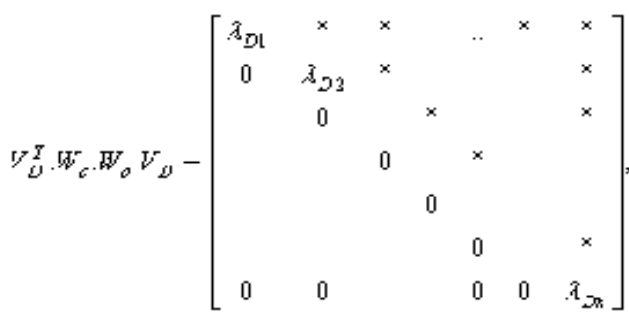

$$
V_{A}^{T} \cdot W_{c} \cdot W_{0} \cdot V_{A}=\left[\begin{array}{ccccccc}
\lambda_{A_{n}} & * & * & . & . & * & * \\
0 & \lambda_{A_{n 1}} & * & . & . & . & * \\
. & 0 & . & * & . & . & * \\
. & . & 0 & . & * & . & . \\
. & . & . & 0 & . & . & . \\
. & . & . & . & 0 & . & * \\
0 & 0 & . & . & 0 & 0 & \lambda_{A_{4}}
\end{array}\right],
$$

Where $\lambda_{A i}=\lambda_{D i}=\sigma_{i}^{2} \quad(i=\overline{1, r})$ 
International Journal of Control Theory and Computer Modelling (IJCTCM) Vol.2, No.6, November 2012

$$
\lambda_{A i}=\lambda_{D i}=\sigma_{i}^{2} \quad(i=\overline{r+1, n})
$$

Step 4: Partition of $V_{A}$ and $V_{D}$ for obtained the matrix $V_{g, g}$ and $V_{d, g}$

$$
V_{A}=\left[\frac{n-r}{V_{d, p}} \underset{g, g}{r}\right], V_{D}=\left[\overrightarrow{V_{d, g}} \frac{n-r}{V} \cdot\right]
$$

The columns of $\mathrm{V}_{\mathrm{d}, \mathrm{g}}$ and $\mathrm{V}_{\mathrm{d}, \mathrm{p}}$ form, respectively, les orthonormal bases for the right eigenspaces of $\left(W_{c} \cdot W_{o}\right)$ associated with big eigenvalues $\sigma_{\mathrm{i}}^{2}(\mathrm{i}=\overline{1, \mathrm{r}})$ and the small eigenvalues $\sigma_{\mathrm{i}}^{2}(\mathrm{i}=\overline{\mathrm{r}+1, \mathrm{n})}$, also, the columns of $\left(\mathrm{V}_{\mathrm{g}, \mathrm{g}}\right)$ and $\left(\mathrm{V}_{\mathrm{g}, \mathrm{p}}\right)$ provide an analogous decomposition of the left eigenspaces.

Step 5: Form the projection

$$
E_{g}=V_{g, g}^{T} V_{d, g},
$$

and compute its singular value decomposition (SVD)

$$
E_{g}=U_{E, g} \cdot \sum_{E, g} \cdot V_{E, g}^{T},
$$

Step 6: Form the matices

$$
\begin{gathered}
S_{g, g}=V_{g, g} \cdot U_{E, g} \cdot \sum_{E, g}^{-1 / 2} \in \mathfrak{R}^{n \times r}, \\
S_{d, g}=V_{d, g} \cdot U_{E, g} \cdot \sum_{E, g}^{1 / 2} \in \mathfrak{R}^{n \times r} .
\end{gathered}
$$

Output: Construction of the low-order model $\left[A_{r}, B_{r}, C_{r}, D\right]$,

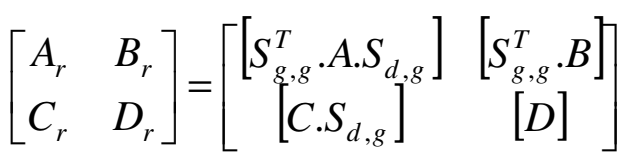

\section{End of procedure.}

\section{FACTOR Division METHOD}

Consider a $\mathrm{n}^{\text {th }}$ order transfer function given by 


$$
G_{n}(s)=\frac{b_{0}+b_{1} s+b_{2} s^{2}+\ldots . .+b_{n-1} s^{n-1}}{\left(s+p_{1}\right)\left(s+p_{2}\right) \ldots . .\left(s+p_{n}\right)},
$$

where $\left(-\mathrm{p}_{\mathrm{i}}, \mathrm{i}=1,2,3, \ldots, \mathrm{n}\right)$ are poles, and $\mathrm{p}_{1}<\mathrm{p}_{2}<\mathrm{p}_{3} \ldots . .<\mathrm{p}_{\mathrm{n}}$.

A reduced transfer function which retains the $(n-1)$ dominant poles and the first time moments of $\mathrm{G}(\mathrm{s})$ is obtained by dividing the factor $\left(\mathrm{s}+\mathrm{P}_{\mathrm{n}}\right)$ into the numerator of $\mathrm{G}(\mathrm{s})$ from the constant term first. This gives the reduced model

$$
G_{n-1}(s)=\frac{d_{0}+d_{1} s+d_{2} s^{2}+\ldots+d_{n-2} s^{n-2}}{\left(s+p_{1}\right)\left(s+p_{2}\right) \ldots\left(s+p_{n-1}\right)}
$$

where

$$
d_{0}=\frac{b_{0}}{p_{n}}
$$

and

$$
d_{i}=\frac{\left(b_{i}-d_{i-1}\right)}{p_{n}},
$$

For a lower-order model, the procedure may be repeated on $\mathrm{G}_{\mathrm{n}-1}(\mathrm{~s})$, and so on until the desired order is reached.

Remark: For an $\mathrm{r}^{\text {th }}$ order model successive of $\mathrm{d}_{\mathrm{i}}, i=\overline{0, r-1}$, only need be calculated from eq. (16). Alternatively, an algorithm can be used for reduction to an r-order.

\section{Factor Division Procedure}

Input: Given a full $\mathrm{n}^{\text {th }}$ order system represented by a transfer-function $G_{n}(s)$.

Step1: Divide the ( $\mathrm{n}-\mathrm{r})$ undesirable poles, verifying

$$
\left(s+p_{r+1}\right)\left(s+p_{r+2}\right) \ldots . .\left(s+p_{n}\right)=e_{0}+e_{1} s+\ldots .+e_{n-r} s^{n-r} \text {, directly into the numerator. }
$$

Step 2: The numerator of the reduced transfer function $\mathrm{G}_{\mathrm{r}}(\mathrm{s})$ is thus given by the series expansion of the expression $A(s)$,

$$
A(s)=\frac{b_{0}+b_{1} s+b_{2} s^{2}+\ldots . .+b_{n-1} s^{n-1}}{e_{0}+e_{1} s+e_{2} s^{2}+\ldots . .+e_{n-r} s^{n-r}},
$$

Step 3: Compute the other coefficients in the following table [3] by using $b_{i}$ and $e_{i}$ coefficients: 


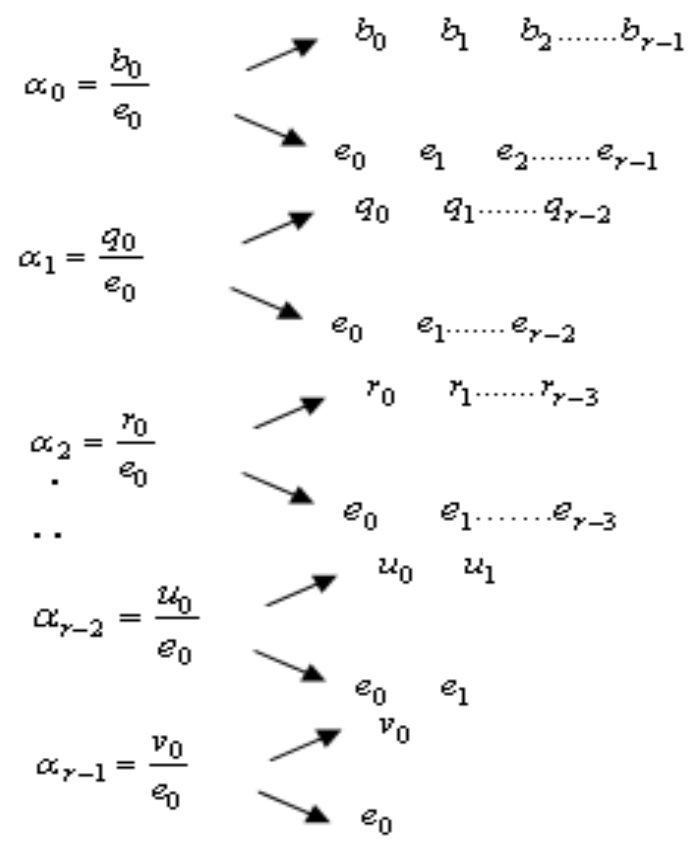

(17)

Where

$$
\begin{aligned}
& q_{i}=b_{i+1}-\alpha_{0} e_{i+1}, i=0,1, . ., r-2, \\
& r_{i}=q_{i+1}-\alpha_{1} e_{i+1}, i=0,1, \ldots ., r-3, \\
& \cdot \\
& \cdot \\
& v_{0}=u_{1}-\alpha_{r-2} e_{1} .
\end{aligned}
$$

Output: The low order model is given by

$$
G_{r}(s)=\frac{\alpha_{0}+\alpha_{1} s+\alpha_{2} s^{2}+\ldots . .+\alpha_{r-1} s^{r-1}}{\left(s+p_{1}\right)\left(s+p_{2}\right) \ldots \ldots\left(s+p_{r}\right)} .
$$

\section{End of procedure.}

\section{FACTOR DIVISION ALGORITHM AND EIGEN SPECTRUM ANALYSIS}

A large number of methods are available in the literature for order reduction of linear continuous systems in time domain as well as in frequency domain [4]. Further, several methods have also been suggested by combining the features of two deferent methods [5]. This technique is based onto combined factor division algorithm to obtain the zeroes of the reduced order model, and eigen spectrum analysis to obtain its poles [7]. Given the transfer function of the high- order $n$ system (HOS), 
International Journal of Control Theory and Computer Modelling (IJCTCM) Vol.2, No.6, November 2012

$$
G_{n}(s)=\frac{N(s)}{D(s)}=\frac{b_{0}+b_{1} s+b_{2} s^{2}+\ldots . .+b_{n-1} s^{n-1}}{\left(s+p_{1}\right)\left(s+p_{2}\right) \ldots .\left(s+p_{n}\right)}
$$

where $-p_{1}>-p_{2}>\ldots . .>-p_{n}$ are poles of HOS

The transfer function low- order system (LOS) of order $r$ is:

$$
G_{r}(s)=\frac{\tilde{N}(s)}{\tilde{D}(s)}=\frac{\alpha_{0}+\alpha_{1} s+\ldots+\alpha_{r-1} s^{r-1}}{\left(s+p_{1}^{\prime}\right)\left(s+p_{2}^{\prime}\right) \ldots .\left(s+p_{r}^{\prime}\right)},
$$

where $-p_{1}^{\prime}>-p_{2}^{\prime}>\ldots . .>-p_{r}^{\prime}$ are poles of LOS.

To construct $\mathrm{G}_{\mathrm{r}}(\mathrm{s})$, the following procedure is proposed.

\section{Procedure [7]}

Input: Given $\mathrm{n}^{\text {th }}$ order system represent by transfer function $G_{n}(s)$.

Step 1: Fixing of eigen spectrum zone of HOS (Fig. 1)

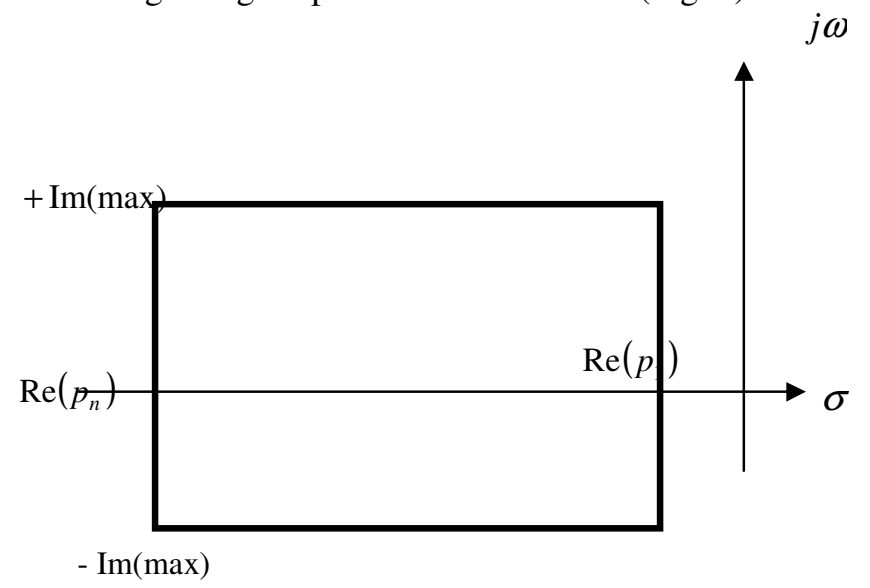

Fig.1. Eigen spectrum zone of HOS

Step 2: Quantification of pole centroid $\mathrm{p}_{\mathrm{m}}$ de HOS:

$$
\mathrm{p}_{\mathrm{m}}=\frac{\sum_{\mathrm{i}=1}^{\mathrm{n}} \operatorname{Re}\left(\mathrm{p}_{\mathrm{i}}\right)}{\mathrm{n}}
$$

and the pole stiffness $p_{s}$ of HOS is 
International Journal of Control Theory and Computer Modelling (IJCTCM) Vol.2, No.6, November 2012

$$
\mathrm{p}_{\mathrm{s}}=\frac{\operatorname{Re}\left(\mathrm{p}_{1}\right)}{\operatorname{Re}\left(\mathrm{p}_{\mathrm{n}}\right)}
$$

Step 3: Compute $p_{m}^{\prime}$ and $p_{s}^{\prime}$ where $p_{m}^{\prime}=p_{m}$ and $p_{s}^{\prime}=p_{s}$

$$
\begin{aligned}
& p_{s}^{\prime}=\frac{\operatorname{Re}\left(p_{1}^{\prime}\right)}{\operatorname{Re}\left(p_{r}^{\prime}\right),}=p_{s} \\
& p_{m}^{\prime}=\frac{\operatorname{Re}\left(p_{1}^{\prime}\right)+\operatorname{Re}\left(p_{2}^{\prime}\right)+\ldots+\operatorname{Re}\left(p_{r}^{\prime}\right)}{r}=p_{m},
\end{aligned}
$$

Step 4 : Compute the $r$ poles of reduce model and M (see Fig. 2) solutions of

$$
\left[\begin{array}{cc}
p_{s}(r-1)+1 & Q \\
\left(1-p_{s}\right) & (1-r)
\end{array}\right]\left[\begin{array}{c}
\operatorname{Re}\left(p_{r}^{\prime}\right) \\
M
\end{array}\right]=\left[\begin{array}{c}
N \\
0
\end{array}\right]
$$

where $N=P_{m} r$ and $Q=r-2$,

and $\mathrm{M}$ is the distance between two successive poles.

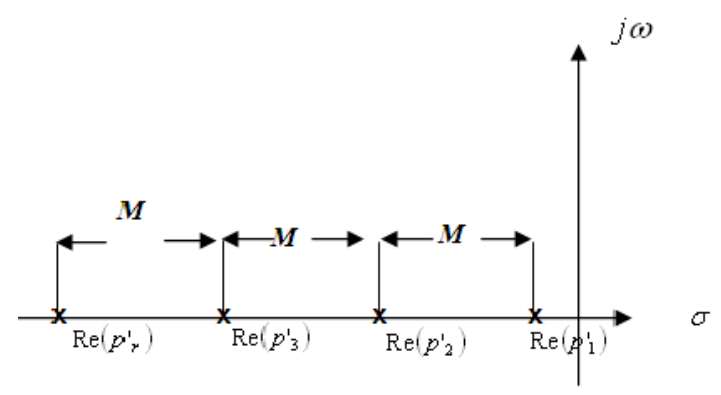

Fig.2. Eigen spectral poles of LOS

Step 5: Using factor division algorithm [6] for calculate $\tilde{\mathrm{N}}(\mathrm{S})$ of equation (19), can be given by:

$$
\frac{N(s)}{D(s)}=\frac{\tilde{N}(s)}{\tilde{D}(s)}
$$

Output : The low order approximant is given by

$$
G_{r}(s)=\frac{\tilde{N}(s)}{\tilde{D}(s)}
$$


International Journal of Control Theory and Computer Modelling (IJCTCM) Vol.2, No.6, November 2012

\section{NUMERICAL APPLICATION}

Consider the partial deferential equation (PDE), representing a continuous, stable system of complete order $n=84$ [12],

$$
\frac{\partial x}{\partial t}=\frac{\partial^{2} x}{\partial z^{2}}+\frac{\partial^{2} x}{\partial v^{2}}+20 \frac{\partial x}{\partial z}-180 x+f(v, z) u(t), \text { where, } x \text { is a function of time (t), vertical }
$$

position $(v)$ and horizontal position $(z)$.

The transfer functions of second order models obtained through proposed and other methods are

$$
\begin{aligned}
& G_{(\text {Troposed })}(s)=\frac{6831 s+1.914 e 005}{s^{2}+703.5 s+1.767 e 004} \\
& G_{(\text {Routh })}=\frac{2018 s+5.903 e 004}{s^{2}+2088 s+5449} \\
& G_{(\text {Schur })}(s)=\frac{2822 s+2.006 e 006}{s^{2}+1030 s+1.85 e 005}
\end{aligned}
$$

After reduction $(r=2)$, we see that the impulse response (Fig. 3), and the step response (Fig. 4) of low order approximant fitted original model. Also, key properties of the initial system are preserved such as stability (Fig. 5) in the reduced order system. To well appreciate the performances of the proposed approach comparing with the others, the distance between original complete order and its approximants is measured in term of integral-square-error (ISE) index error (Table 3):

Table 3 - Comparison of integral-squared-error (ISE)

\begin{tabular}{|c|c|}
\hline $\begin{array}{c}\text { Reduced order Models } \\
\text { from: }\end{array}$ & ISE \\
\hline Schur method & $8.191 \mathrm{e}-005$ \\
\hline Proposed method & $5.441 \mathrm{e}-003$ \\
\hline Routh method & $1.01 \mathrm{e}-002$ \\
\hline
\end{tabular}


International Journal of Control Theory and Computer Modelling (IJCTCM) Vol.2, No.6, November 2012

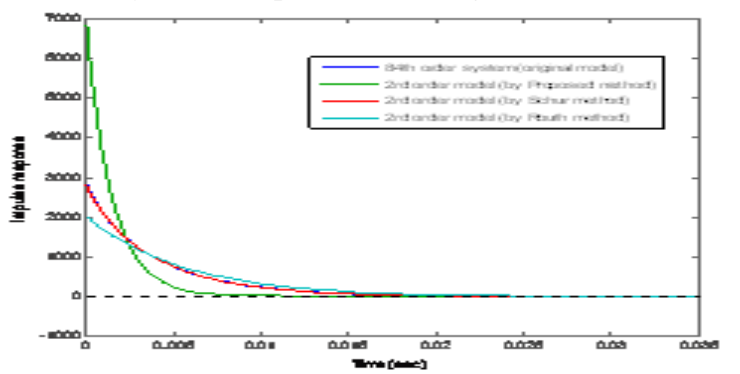

Fig. 3. I mpulse responses of original system and its approximants

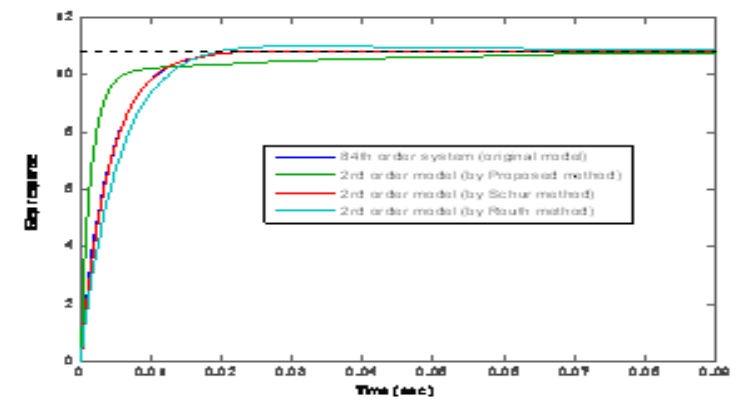

Fig. 4. Step responses of original system and its poroximants

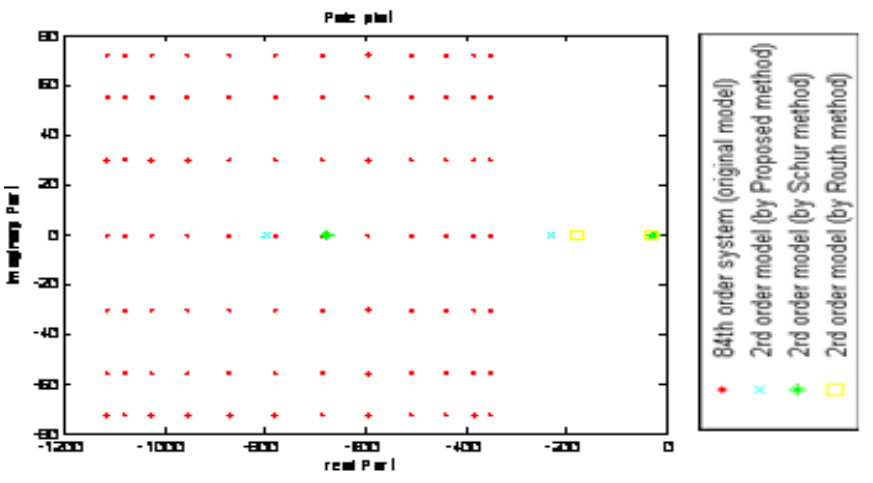

Fig. 5 Poles of original and reduced order models

For the previous example, we have shown the frequency responses by plotting the amplitude spectra (dB) and the phase spectra (Fig. 6), and the singular values distribution (Fig. 7), according to the low order $r$. The graphs show that the approximants closely follow the global behavior of the initial system. It should be noted as even a slight deviation; these errors are due to a substantial reduction of order. 
International Journal of Control Theory and Computer Modelling (IJCTCM) Vol.2, No.6, November 2012

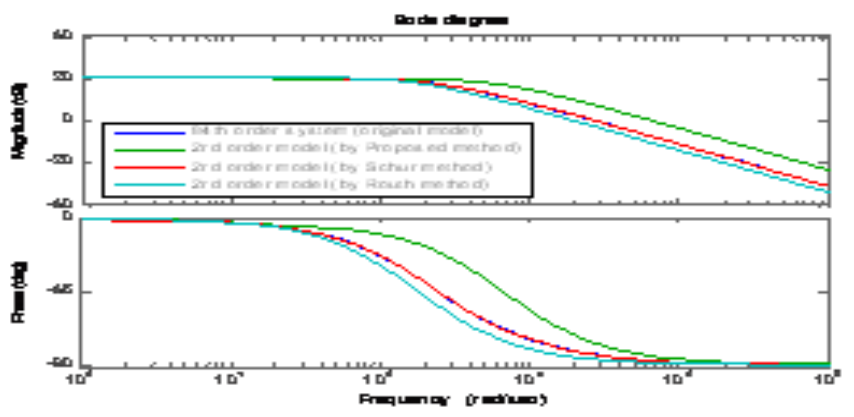

Fig. 6. Frequency responses (dB) of original svstem and its approximants

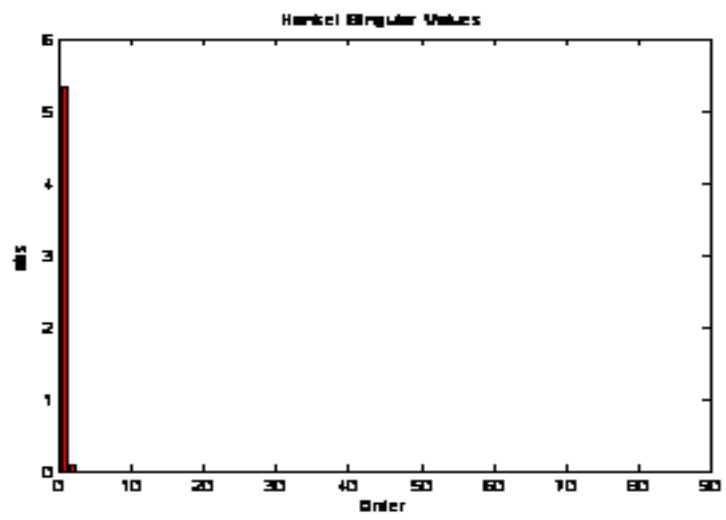

Fig. 7. Hankel singular values

To appreciate the distance between initial model and its approximants from the model order reduction, an integral index error is calculated. It reveals that the proposed technique is interesting but not the best.

\section{CONClusion}

This work is based on the approximation of high order system, using the factor division algorithm and eigen spectrum analysis.A simulation is performed and compared to other techniques mentioned in this paper. We note that the reduced order approximation by proposed method keeps the key properties of the original system and from the error criterion ISE and frequency and time responses, our approximation yields to a good model rather than Routh technique, but once again, the Schur technique prove its superiority [13].

\section{REFERENCES}

[1] B. C. Moore, Principal component analysis in linear systems: Controllability, observability, and model reduction, IEEE Trans. Automat. Contr. AC-26 (1981) 17-32.

[2] A. Laub, M. T. Heath, C. C. Paige, R. C. Ward, Computation of systems balancing transformations and other applications of simultaneous diagonalization algorithms, IEEE Trans. on Automat. Contr. AC-32 (1987) 115-122. 
International Journal of Control Theory and Computer Modelling (IJCTCM) Vol.2, No.6, November 2012

[3] M. Lal e\& R. Mitra, Simplification of large system dynamics using a moment evaluation algorithm , IEEE Trans., 1974, AC-19, pp.602-603.

[4] R. Geneso 1 M.Milanese, A note on the derivation and use of reduced order models, IEEE Trans. Automat. Control AC-21 (1), (1976) 118-122.

[5] B.Slimbahrami \& B Lohmann, Order reduction of large scale second-order systems using Krylov subspace methods, Linear Algebra , Appl. 415 (2006) 385-405.

[6] T. N. Lucas, Factor division: a useful algorithm in model reduction , IEE Proc. 130 (6) (1983) 362364.

[7] G. Parmar, S. Mukherjee \& R. Prasad, System reduction using factor division algorithm and eigen spectrum analysis, Science direct Applied Mathematical Modelling, 31 (2007) 2542-255.

[8] V. Krishnamurthy \& V. Sheshadri, Model reduction using Routh stability criterion ", IEEE Trans. Autom. Control, 1978, 23, pp. 729-731.

[9] L. Mitiche \& A. B. H. Adamou, Schur method for Model reduction non minimal case, International Conference on Signals and Systems, Vol. 2, pp. VI.63-VI.66, Algiers Sept. 24-26, 1994.

[10] K. Glover, All optimal Hankel-norm approximations of linear multivariable systems and their L $\infty$ error bounds, International Journal of Control, Vol. 39, No. 6, pp. 1115-1193, 1984.

[11]M. G. Safonov \& R.Y.Chiang, A Schur method for Balanced-truncation model reduction, IEEE Transaction on Automatic Control, vol.34 N 07 July 1989.

[12]E. J. Grimme, Krylov Projection Methods for Model Reduction, Ph. D in the Graduate College of the University of Illinois at Urbana-Champaign, 1997.

[13]A. B. H. Adamou-Mitiche and L. Mitiche, Comparative study of model reduction schemesapplication to the digital filters synthesis, in Proceeding of the IEEE Sixth International symposium on Signal Processing and its Applications ISSPA 2001, Kuala Lumpur, Malaysia, 13-16 August, 2001, Vol. 2, pp. 675-678.

\section{Authors:}

\section{Amel Baha Houda Adamou-Mitiche}

She received her state Engineering degree in Electronics from the Ecole Nationale Polytechnique of Algiers (ENPA), Algeria, her Master of Science degree in Electronics from University Houarie Boumédiènne of Algiers, and her Doctorat d'Etat (Ph. D.) degree in Control Systems (ENPA). She is Associate Professor in Sciences and Technology Department, University of Djelfa, Algeria. Her major research interest include descriptor and singular systems, model approximation, model order reduction using various approaches, digital signal processing.

\section{Lahcène Mitiche}

$\mathrm{He}$ received her state Engineering, the Master of Science, and his $\mathrm{Ph}$. D. degrees, all in Electronics Engineering, from the Ecole Nationale Polytechnique of Algiers, Algeria (ENPA). Currently, he is an Associate Professor in Signal Processing, and head of Sciences and Technology Department, University of Djelfa, Algeria. His major research interest include model order reduction with several applications to large scale analog and digital systems, speech coding, low order speech synthesis, and 2D digital filters approximation.
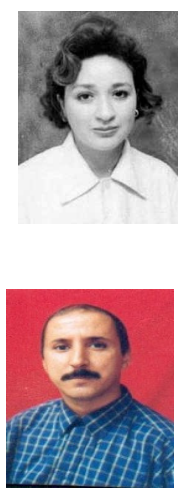